Original Research Paper

\title{
Copper and Zinc Serum Level in Patients Receiving Hemodialysis
}

\author{
${ }^{1}$ Rahim Raoofi, ${ }^{1}$ Hossein Hakimelahi, ${ }^{1}$ Mohammad Sadegh Sanie, ${ }^{2}$ Alireza Yousefi, \\ ${ }^{1}$ Abdolreza Sotoodeh Jahromi, ${ }^{2}$ Akbar Kazemi, ${ }^{1}$ Hassan Zabetian and ${ }^{3}$ Abdolhossein Madani \\ ${ }^{I}$ Research Center for Non. Communicable Diseases, Jahrom University of Medical Sciences, Jahrom, Iran \\ ${ }^{2}$ Research Center for Social Determinant of Health, Jahrom University of Medical Sciences, Jahrom, Iran \\ ${ }^{3}$ Research Center for Social Determinants of Health Promotion, Hormozgan University of Medical Sciences, Bandarabbas, Iran
}

Article history

Received: 28-04-2015

Revised: 23-06-2015

Accepted: 14-07-2015

Correspondence Address: Akbar Kazemi

Research Center for Social

Determinant of Health, Jahrom

University of Medical

Sciences, Jahrom, Iran

E-mail: sotoodehj2002@yahoo.com

\begin{abstract}
Decreased kidney function can accumulate trace elements. Increased trace elements can have toxic features. On the other hand, studies are showing that concentration of some trace elements could be decreased in chronic kidney disease patients as well. Because these patients are at risk for alterations of trace elements, we measured serum level of zinc and copper trace elements in hemodialysis patients and compare it with the control group. We analyzed the trace elements' copper and zinc concentration in the whole blood of 52 ESRD patients who were treated with hemodialysis as case group and also of 52 age and sex matched healthy people as control group. Whole blood trace element concentration was determined by atomic absorption spectrometry. The serum concentrations of zinc and copper were significantly lower in case group compared to control group. The serum concentration of zinc and copper trace elements in end-stage renal failure patients is disturbed. Due to the discrepancy in findings of different studies, further studies in large scale are recommended to determine the serum concentration of trace elements in these patients.
\end{abstract}

Keywords: Hemodialysis Patients, Zinc, Copper, Iran

\section{Introduction}

Uremia is recognized by functional and biochemical disturbances that are primarily a result of reduced kidney capacity to clear body from organic solutes. Most studies on uremic toxicity have focused on retention and removal of these organic compounds. However, subtle changes in the concentrations of inorganic compounds, including trace elements, may also cause functional or biochemical disturbances (Vanholder et al., 2002; Prodanchuk et al., 2013).

In End-Stage Renal Disease (ESRD) patients, different factors affect whole blood and serum level of trace elements, such as increased oral intake, failure of renal excretion, grade of renal failure and metabolic changesrelated with renal failure (Miura et al., 2002).

Hemodialysis is the most common modality of renal replacement therapy. Unfortunately, dialysis is associated with considerable morbidity and mortality due to cardiovascular disease and infection (Henderson and Beans, 1978).

Hemodialysis patients are at risk for both deficiency and accumulation of trace elements, depending on dietary intake, removal by dialysis, the composition of the source water used for hemodialysis and residual kidney function (D'haese and De Broe, 1996; Zima et al., 1999).

The trace elements have a role in infection control through the immune system function. Deficiency of micronutrients like vitamins, iron, zinc and copper are the most important reasons for immunodeficiency (Foreman et al., 1996).

Regarding what has been said, it can be concluded that copper as a micronutrient has a vital role. In addition, reduced serum level of copper (CunninghamRundles et al., 2005) and zinc (Hsieh et al., 2006) in dialysis patients, Therefore, serum levels copper and zinc should be determined in hemodialysis patients.

Achieved information about trace element disorders in ESRD patients receiving hemodialysis could assist in 
the process of developing a microelement improvement approach. Thus, it would recover the nutritional status of these patients.

In this research, we intend to determine the serum level of copper and zinc in hemodialysis patients and compare with serum level of these trace elements in healthy people.

\section{Materials and Methods}

This case-control study was carried out on dialysis patients referring to Jahrom Dialysis Center May 2013 to August 23, 2013. Fifty two dialysis patients visiting Jahrom Dialysis Center as case group and 52 sex and age matched healthy people (having normal serum creatinine and BUN levels) as control group were enrolled to this study.

This research work was approved by ethics research committee of Jahrom University of medical sciences.

Blood samples $(3 \mathrm{cc})$ of the both groups were taken and isolated sera were kept at $-20^{\circ} \mathrm{C}$. Serum level copper and zinc were determined by atomic absorption method by Perkin-elemer A300.

All demographic information of the case and the control groups was kept confidential and all examinations were free of charge.

At the end, all checklist information was fed into SPSS16 and analyzed statically; using t-test, chi-square test and descriptive analysis.

\section{Results}

Among the 52 dialysis patients, $35(67.30 \%)$ and 17 $(32.70 \%)$ subjects were male and female, respectively, with the mean age of $57.75 \pm 4.26$ years. In the control group, $34(65.40 \%)$ and $18(34.60 \%)$ subjects were male and female, respectively, with the mean age of $58.98 \pm 14.32$ years. There was no statistically significant difference between the two groups in terms of mean age and gender frequency $(\mathrm{p}>0.100)$.

In the case group, dialysis therapy duration was $25.55 \pm 25.67$ months.

The serum concentrations of zinc and copper were significantly lower in case group compared to control group (Table 1).

There was no statistically significant difference in serum level of copper between male and female in the case and the control groups (Table 2).

Also there was no statistically significant difference in serum level of zinc between male and female in the case and the control groups (Table 3).

The results showed an inverse relationship between the serum level of copper and zinc, with age in case group, but it was not statistically significant $(\mathrm{r}=-0.033$, $\mathrm{P}=0.819)$ and $(\mathrm{r}=-0.164, \mathrm{P}=0.244)$, respectively. The same result was observed in the control group $(\mathrm{r}=$ $0.036, \mathrm{P}=0.802)$ and $(\mathrm{r}=-0.075, \mathrm{P}=0.595)$ respectively for copper and zinc.
Table 1. Copper and Zinc Serum level in the study groups

\begin{tabular}{lll}
\hline Trace element & Copper $(\mu \mathrm{g} / \mathrm{dL})$ & Zinc $(\mu \mathrm{g} / \mathrm{dL})$ \\
\hline Case group Mean $\pm \mathrm{SD}$ & $58.30 \pm 21.95$ & $78.04 \pm 30.57$ \\
Control group Mean $\pm \mathrm{SD}$ & $106.01 \pm 56.88$ & $113.53 \pm 41.44$ \\
p-value & 0.001 & 0.001 \\
\hline
\end{tabular}

Table 2. Serum level copper in male and female in both groups

\begin{tabular}{lll}
\hline Copper $(\mu \mathrm{g} / \mathrm{dL})$ & Case group Mean \pm SD & Control group Mean \pm SD \\
\hline Male & $57.18 \pm 94.54$ & $63.26 \pm 121.70$ \\
Female & $79.59 \pm 38.23$ & $53.26 \pm 99.04$ \\
p-value & 0.567 & 0.188 \\
\hline
\end{tabular}

Table 3. Serum level copper and zinc in male and female in both groups

\begin{tabular}{lll}
\hline Zinc $(\mu \mathrm{g} / \mathrm{dL})$ & Case group Mean \pm SD & Control group Mean $\pm \mathrm{SD}$ \\
\hline Male & $75.75 \pm 30.31$ & $119.46 \pm 47.05$ \\
Female & $83.20 \pm 31.53$ & $100.18 \pm 20.01$ \\
p-value & 0.420 & 0.123 \\
\hline
\end{tabular}

An inverse relationship was observed between the serum level copper and zinc with duration of dialysis therapy in the case group. Patients with longer dialysis history had lower serum level of copper and zinc, which were statistically significant $(\mathrm{r}=-0.444, \mathrm{P}=0.001)$ and $(\mathrm{r}$ $=-0.330, \mathrm{P}=0.017)$, respectively.

\section{Discussion}

Our data shows that the decreasing amounts of the trace elements copper and zinc in blood levels is observed for hemodialysis patients, in comparison with healthy people. This result has an agreement with previous study in Spain (Cunningham-Rundles et al., 2005) and another research in Taiwan (Hsieh et al., 2006) but it is inconsistent with the result of NavarroAlarcon study. Their findings showed that the zinc serum level in hemodialysis patients was higher than normal people, which was not statistically significant (Navarro-Alarcon et al., 2006). They attributed this to blood doping or release of copper in dialysis membrane (Oh and Meyerhoff, 2004; De La Torre et al., 2014).

In present study, there was no significant correlation between the serum level copper and zinc with the factors age and gender, which agreed with other studies (Navarro-Alarcon et al., 2006; Churchwell et al., 2007).

In this study, the serum level copper and zinc in female and male groups was not significantly different in the case and in the control groups. Similar results were observed in other research (Anees et al., 2011). Yet, findings of Navarro-Alarcon et al. (2006) contradicted ours, as that level was significantly higher among the investigated men than women.

Incorrect implementation of dialysis process, including disorder in the concentration ratio of blood and dialysis fluid or in permeability of dialysis membrane, can reduce the level of trace element. However, other cases including loss of appetite and decreasing in daily 
food intake can be other influential reasons. Paying attention to this further signifies the very important and vital role of such trace elements (copper, zinc) for these patients (Anees et al., 2011).

Also, some studies said that the copper serum level did change during dialysis process (Johnson and Kays, 1990; Ikee et al., 2012; De la Torre et al., 2014).

Regarding on this matter, the relationship between the dialysis processes with trace elements serum level is controversial. Although, the findings of this study show the level reduction, further investigations are recommended.

In this study, an inverse association was observed between the serum level copper and zinc and age in the both groups. Since this relationship was not significant in any of the two investigated groups, it could be concluded that aging did not affect the copper and zinc serum level.

In this study, an inverse statistically significant relationship was observed between the serum level of copper and zinc with the history hemodialysis therapy in the case group, which was consistent with previous study (Lönnerdal, 1998; Bhogade et al., 2013). On the other hand, other results of this study were inconsistent with the result of Kaliuzhinas research (Kaliuzhina et al., 2005).

Some important roles of copper and zinc in the body include: The presence in biological enzymes as cofactors including anti-oxidant, electron carriers, clotting enzymes, etc. (Kaliuzhina et al., 2005); its role in human health like infection control through the immune system, inhibition of viral replication (Girndt et al., 1993), improving the function of $\mathrm{T}$ lymphocyte (Vacher-Coponat et al., 2008), in vivo cooperation for cell-mediated immune response.

Although, hemodialysis facilities the symptoms and signs of ESRD, it does not change the disease natural flow and faces the patients with several complications. Some of those problems are the direct outcomes of the hemodialysis process.

\section{Conclusion}

This study aims at investigating the serum level trace elements in ESRD, since copper and zinc have an important role in health, as mentioned. Therefore, disorder in their level can lead to several problems to the dialysis patients who are prone to several infections and other diseases. According to our results, the serum level of copper and zinc were significantly lower in the case group than healthy people. Therefore, it can be concluded that the use of copper and zinc supplement for such patients is essential for preventing further complications. However, further investigations in that area are recommended.

\section{Acknowledgment}

The authors wish to thank Jahrom University of Medical Sciences for supporting this study.

\section{Funding Information}

This work has been financed by Jahrom University of Medical Sciences.

\section{Competing Interests}

The authors declare that they have no competing interests.

\section{Author's Contributions}

All authors have read and approved the final manuscript.

Rahim Raoofi, Abdolreza Sotoodeh Jahromi and Akbar Kazemi: Participated in Designed the study, data collection and contributed to the revision of the manuscript.

Alireza Yousefi, Hassan Zabetian, Hossien Hakimelahi, Mohammad Sadegh Sanie and Abdolhossein Madani: Carried out data collection, determination of copper and zinc serum levels, analysis and writing the manuscript

\section{Ethics}

The identity of all subjects who participated in this research will be kept anonumus.

\section{References}

Anees, M., A. Mumtaz, S. Frooqi, M. Ibrahim and F. Hameed, 2011. Serum trace elements (aluminium, copper, zinc) in hemodialysis patients. Biomedica, 27: 106-110.

Bhogade, R.B., A.N. Suryakar and N.G. Joshi, 2013. Effect of hemodialysis on serum copper and zinc levels in renal failure patients. Eur. J. Gen. Med., 10: 154-157.

Churchwell, M.D., D.A. Pasko, I.F. Btaiche, J.C. Jain and B.A. Mueller, 2007. Trace element removal during in vitro and in vivo continuous haemodialysis. Nephrol. Dialysis Transplantation, 22: 2970-2977. DOI: $10.1093 / \mathrm{ndt} / \mathrm{gfm} 352$

Cunningham-Rundles, S., D.F. McNeeley and A. Moon, 2005. Mechanisms of nutrient modulation of the immune response. J. Allergy Clin. Immunol., 115: 1119-1128. DOI: 10.1016/j.jaci.2005.04.036

De la Torre, M.L.R., M. Navarro-Alarcón, L.M. del Moral, H.L.G. de la Serrana and M. Palomares-Bayo et al., 2014. Serum zn levels and cu/zn ratios worsen in hemodialysis patients, implying increased cardiovascular risk: A 2-year longitudinal study. Biol. Trace Element Res., 158: 129-135. DOI: $10.1007 / \mathrm{s} 12011-014-9921-\mathrm{y}$ 
D'haese, P. and M. De Broe, 1996. Adequacy of dialysis: Trace elements in dialysis fluids. Nephrol. Dialysis Transplantation, 11: 92-97.

DOI: $10.1093 /$ ndt $/ 11$.supp2.92

Foreman, J.W., C.L. Abitbol, H. Trachtman, E.H. Garin and L.G. Feld et al., 1996. Nutritional intake in children with renal insufficiency: A report of the growth failure in children with renal diseases study. J. Am. College Nutr., 15: 579-585. DOI: 10.1080/07315724.1996.10718633

Girndt, M., H. Köhler, E. Schiedhelm-Weick, K.M.Z. Büschenfelde and B. Fleischer, 1993. T cell activation defect in hemodialysis patients: Evidence for a role of the $\mathrm{b} 7 / \mathrm{cd} 28$ pathway. Kidney Int., 44: 359-359. DOI: 10.1038/ki.1993.252

Henderson, L.W. and E. Beans, 1978. Successful production of sterile pyrogen-free electrolyte solution by ultrafiltration. Kidney Int., 14: 522-525. DOI: 10.1038/ki.1978.157

Hsieh, Y.Y., W.S. Shen, L.Y. Lee, T.L. Wu and H.C. Ning et al., 2006. Long-term changes in trace elements in patients undergoing chronic hemodialysis. Biol. Trace Element Res., 109: 115-121. DOI: 10.1385/BTER:109:2:115

Ikee, R., M. Tsunoda, N. Sasaki, M. Sato and N. Hashimoto, 2012. Clinical factors associated with serum copper concentration in patients on hemodialysis. Kidney Res. Clin. Practice, 31: A38- A38. DOI: 10.1016/j.krcp.2012.04.410

Johnson, M.A. and S.E. Kays, 1990. Copper: Its role in human nutrition. Nutrition Today, 25: 15-19.

Kaliuzhina, E., O. Geĭnits, V. Kaliuzhin and I. Pak, 2005. The condition of immune homeostasis in patients with chronic renal failure. Klinicheskaia Meditsina, 84: 60-63. PMID: 17243614

Lönnerdal, B., 1998. Copper nutrition during infancy and childhood. Am. J. Clin. Nutr., 67: 1046S-1053S. PMID: 9587150
Miura, Y., K. Nakai, A. Suwabe and K. Sera, 2002. Trace elements in renal disease and hemodialysis. Nuclear Instruments Methods Phys. Res. Section B: Beam Interact. Mater. Atoms, 189: 443-449. DOI: 10.1016/S0168-583X(01)01122-3

Navarro-Alarcon, M., A. Reyes-Perez, H. Lopez-Garcia, M. Palomares-Bayo and M. Olalla-Herrera et al., 2006. Longitudinal study of serum zinc and copper levels in hemodialysis patients and their relation to biochemical markers. Biol. Trace Element Res., 113: 209-222. DOI: 10.1385/BTER:113:3:209

Oh, B.K. and M.E. Meyerhoff, 2004. Catalytic generation of nitric oxide from nitrite at the interface of polymeric films doped with lipophilic CU (ii)complex: A potential route to the preparation of thromboresistant coatings. Biomaterials, 25: 283-293. DOI: 10.1016/S0142-9612(03)00530-1

Prodanchuk, M., O. Makarov, E. Pisarev, B. Sheiman and M. Kulyzkiy, 2013. Disturbances of trace element metabolism in esrd patients receiving hemodialysis and hemodiafiltration. Central Eur. J. Urology, 66: 472-476. DOI: $10.5173 /$ ceju.2013.04.art23

Vacher-Coponat, H., C. Brunet, L. Lyonnet, E. Bonnet and A. Loundou, 2008. Natural killer cell alterations correlate with loss of renal function and dialysis duration in uraemic patients. Nephrol. Dialysis Transplantation, 23: 1406-1414. DOI: $10.1093 / \mathrm{ndt} / \mathrm{gfm} 596$

Vanholder, R., R. Cornelis, A. Dhondt and N. Lameire, 2002. The role of trace elements in uraemic toxicity. Nephrol. Dialysis Transplantation, 17: 2-8. DOI: $10.1093 /$ ndt/17.suppl_2.2

Zima, T., V. Tesař, O. Mestek and K. Němeček, 1999. Trace elements in end-stage renal disease. Blood Purification, 17: 187-198. DOI: 10.1159/000014394 